\title{
On living in a techno-globalised world: Questions of history and geography
}

\section{David Morley}

My starting point is that much of media and communication studies, as presently constituted, suffers from a drastically foreshortened historical perspective, the absence of which is all the more critical now, as we enter the word of the digital media. Thus I argue that media studies needs to place contemporary developments, such as the constitution of cyberspace - with which much contemporary work is concerned - in a much longer historical perspective. As we now enter an era of digitalisation, technical convergence, individualised and interactive media systems, all these issues become all the more urgent. As Spigel (2004) has put it, the more we speak of futurology, the more we need to take a longer historical perspective on these issues. In this context we must neither be 'suckered' into believing all the hype about how much the new media are going to change the world, nor being too cynical by insisting that we have 'seen it all before'. The key question here is how to see contemporary changes in media cultures in historical perspective.

We are often told that, under the impact of the new technologies of our globalised age we live increasingly in a borderless world, characterised by unprecedented rates of mobility, and by the experience of time-space compression, resulting from the speed of communications and transport links. To this extent, we are offered an image of brand new world of 'all at once- ness', which is remarkably similar to Marshal McLuhan's 1960s image of the 'global village' of 'instantaneity'. New technologies and global cultural flows now transgress the boundaries around our nations, localities and homes, in so far as the media continually flood us with images of hitherto unknown people and places. However, we should not mistake these media's 'reach' for their 'power'. They may be almost ubiquitous, but theirs is often a rather 'thin' presence, diluted by local contexts of reception. Thus global cultural forms still have to be made sense of within the context of local forms of life. 
In some versions of the story of globalisation, we are offered what I would characterise as an abstracted sociology of the postmodern, inhabited by an un-interrogated 'we', who 'nowadays' live in an undifferentiated global world. Moreover, the presumption is that our lives are increasingly determined by the effects of the 'new media'. From my own point of view, this is particularly problematic, as the technologically determinist nature of the claims made for the (seemingly) 'automatic' effects of the new media fly in the face of the last 30 years of audience research, which has demonstrated the very complex ways in which different media technologies are, in fact, interpreted and mobilised by their users. It is curious that the discussion of new media often returns us to an outmoded discourse of 'automatic' media effects, whether from a dystopian or utopian point of view. My argument is that what we need is a perspective on how a variety of media technologies, both new and old, are fitted into, and come to function within, a variety of different cultural contexts.

That kind of 'contextualist' approach to questions of technological change is defined by Bryce (1987) as one in which, rather than starting with the internal 'essence' of a technology and then attempting to deduce its 'effects' from its technical specifications, one begins with an analysis of the interactional system in a particular context and then investigate how any particular technology is fitted into it.

Clearly, no technology has straightforward impacts - not least because one has to begin with the question of which people (differentially) see the relevance (or irrelevance) of any given technology to them and how they ignore, or mobilise and use it, in the specific cultural context of their own lives. This approach evidently shares much with the anthropological concept of consumption as a form of 'domestication' (or indigenisation) of technologies - by which the objects are effectively 'customised' by being fitted into local patterns of use. This emphasis is also similar to that of the 'circuit of culture' model developed by Stuart Hall and his colleagues at the Open University (du Gay et al., 1996), which likewise argues that context is no 'optional extra', which we might study at the end of the analytic process, but rather, is best seen a 'starting point' - which has determining effects on both production and consumption. 


\section{Grounded theories of technology in context}

In relation to the broader questions of technology and context, my general point concerns the need to focus not on digitalisation in general, or on cyberspace in the abstract, but rather on the particular types of cyberspaces which are instituted in specific localities, under particular cultural, economic and political circumstances. This is to follow the example set by Miller and Slater (2000), in their study of the internet in Trinidad - as a way of studying how the worlds of the virtual and the actual are differently integrated across the globe in specific contexts. To take a further example of the importance of how a particular technology is instituted in a particular context, elsewhere Slater examines the contrasting cases of two villages in western Africa. In the first village, a large amount of 'aid' money was acquired and a customised hall was built to house some of the latest, high-speed-modem computers, in a purpose-built, fully airconditioned environment. Unfortunately, the hall was built in a slightly out-of-the- way location, which did not connect well with the customary pathways along which the local villagers travelled, and so this powerful technology was rather underused. In the second case, a returning Western 'volunteer' left behind, in the village he'd worked in, a clapped-out laptop with a dodgy modem, giving it to the owner of a local cafe, who set it up on one of the tables in the back of his bar. Although this was a much less powerful piece of technology, the cafe where it was sited had, directly outside it, the bus stop and the taxi rank where the local people from the other villages around passed through, on their way to market. As a result of it 'fitting' much more effectively with the established communications systems of the community in which it was sited, this less powerful technology had much more con- sequential effects than the purpose-built computers in the air-conditioned environment in the other village.

For these kind of reasons, I am very much in favour of returning to the classical definition of communications, which would re-incorporate the study of physical movement within its remit. Thus, rather than focussing exclusively on the trans- mission of messages, which is what we tend to think of these days, when we say 'communications', we might better consider how these questions can be articulated with questions of transport. This would then be to incorporate the study of the movement of 
people, and commodities, and technologies alongside that of information - and contemporaneously, place the study of the emerging virtual realms alongside that of the material world (cf. Morley, 20I I).

\section{Theories of techno-globalisation; questions of regionality and periodisation}

Theories of globalisation often emphasise the role of communications technologies in the process of time-space compression and de-territorialisation. In this model, the virtual world is sometimes then argued to have so thoroughly 'replaced' the physical world that geography is declared to be dead. However, all of this is evidently based on rather simplistic ideas about the transformative effects of digital technologies. Coming, as I do, from a cultural studies tradition which prioritises 'grounded' theory and emphasises specificity in empirical investigations, I find myself unsympathetic to the kind of abstracted 'One-Size-Fits-All' analyses of globalisation-thru-technology which dominate the field today.

Rather than generalist schemes, which try to reduce the whole of history to one Big Story, we may perhaps be better served by some differentiations between the stories and perspectives of a variety of regions, areas and periods. However, if we are to attempt to produce a more concretely regionalised perspective on globalisation, there is a difficulty with the definition of the units of analysis to be used. In this context, we shouldn't simply take geographical 'areas' as the units of our cartography (nor presume that, within each one, we will find only one set of exclusive or 'dominant' properties). Rather, we should take the relevant cultural, political and economic forms as the basic units of analysis and then look to see where they are to be found, without assuming that they are 'naturally' bound to any particular geography.

The further problem concerns just how new all this global mobility and technical change is. Edgerton (2006) notes that we are often told that we are entering a new historical epoch, in which change takes place at an ever increasing rate, as result of the effects of increasingly powerful technologies. However, we can perfectly well be argued to live in an age of technological stasis, relatively speaking, compared with the speed of 
technological change at the beginning of the twentieth century (the era of the invention of radio, the cinema, photography, the steamship, the railroad and the aeroplane). As Edgerton points out, judging by these standards, the present does not in fact seem particularly innovative. Most historians tend to focus exclusively on technological novelty, while in reality, it is older technologies which continue to dominate our lives. Moreover, our accounts of technology are fundamentally unbalanced by a tendency to focus on invention over use, acquisition over maintenance, and inevitability over choice, when what matters more is how technologies are used and by whom, as they are transformed and 'reinvented' in hybrid forms, and their use shifts from one context to another.

Moreover, this is often a process of uneven development, in which technologies which may have declined for a period in one context, re-emerge later as the most important technologies of the era, in other places. Consider how the bicycle declined in the West in the late C20th, re-emerging much later in the cities of the 3rd World and then returning to the West, in its new ecological incarnation. Indeed, despite the claims of the innovation-centric, technological futurism on which our present visions are based, some areas of the world have recently experienced significant technological regression for in- stance, in the return of animal-drawn farm implements in countries which previously would have used tractors; or in the transformation of the previously hi-tech shipbreaking industry into one which now takes place on the beaches of Bangla- desh, where armies of men break up modern ships up for scrap, using mediaeval implements (Buerk, 2006). These issues also raise the eternally vexed question of historical periodisation. Many technologies that we think of as 'old' - the donkey cart, the wooden plough - have been maintained and used throughout the last century in many places, often alongside the aeroplane and the motorcar. As we know, old technologies often achieve new forms of symbiosis with more contemporary ones.

Thinking about the history of technology-in-use - and concentrating on the adaptation, operation and maintenance of things - offers us a very different perspective from that of the innovation-centred model. Firstly, it offers us a truly global history, rather than focussing exclusively on the small number of (largely Western) places where invention 
has been historically concentrated. By this means, we can then shift our attention away from the large-scale, spectacular, masculine, prestigious technologies of the rich white world, to also bring into focus the small-scale, mundane, feminised, and often creolised technologies of the shanty towns of the world - which are the products not of professional scientists, but of millions of untutored, but inventive amateur architects, engineers and builders. When we think of these vernacular architectures, we need to ask not simply what 'standard' facilities the shanty towns lack, but rather, what (often novel) systems for the supply of necessities they have developed, in order to sustain a new kind of rapidly expanding urban existence on an enormous scale, even if only at subsistence level (cf Edgerton op cit). These systems will often be adaptations of older, imported technologies from elsewhere, now given a new lease of life and adapted for local use (such as the tin drum, flattened into roof or wall; or the scooter crossed with the rickshaw to produce the tuk-tuk taxis of Thailand). More importantly these technologies at the heart of the fastest growing cities, such as Lagos and Mumbai - the places where the modernity of the future is already taking shape.

These issues bring us to the eternally vexed question of how to address the question of periodisation in our work. Braudel (1984) always insisted on the need to recognise the simultaneous existence of different temporalities - just as Williams (1965) noted the coexistence of residual, dominant and the emergent tendencies within any one historical period. Thus, as Latour (1993) argues, 'modern time', in any pure form, has never existed - for the eras of the traditional, the modern and the postmodern have always been jumbled up and we have always worked with a mixture of old and new technologies, simultaneously utilising Paleolithic inventions such as hammers and nails alongside contemporary cordless electric drills. In a similar spirit, Bausinger (1990) rightly argues that we need to explore the extent to which folk culture is alive and well in the world of modern technology.

\section{The geography of cyberspace: questions of speed and instantaneity}

As I noted earlier, in recent years, a variety of technologies have been said to have transformed our lives - to the extent that we are held to be living in a new era of space/time compression, characterised by the wholesale 'disembedding' of cultural, 
economic and political activities. Some have claimed that in this cybernetic world 'we no longer have roots or origins - only aerials and terminals'; and that 'we' now live in a world where geography no longer counts for much (Wark, 1994).

In these arguments about the 'death' of geography, one example which is often cited is the growth of the telephone 'call- centres', based in India which, now handle a lot of the 'customer services' calls for a variety of British businesses. However, while these call centres no longer need to be on the geographical territory of the UK, in order to deal effectively with British customers, they are not, as it were 'just anywhere'. They are located precisely where they are because India can offer investors the attractive combination of a high level of indigenous English language skills alongside a low-wage economy, as the direct result of the long history of Britain's imperial presence on Indian soil. It is for reasons of exactly the same kind that French and Spanish call centres tend to be located in North Africa. The supposedly 'de-territorialised' geography of our postmodern era is thus much more legible if one reads it as a set of 'shadow' geographies created through the complex history of imperialism.

Morever, despite the widespread dissimulations of 'placelessness' practised in these callcentres, cyberspace still has a very real geography. The relative density of internet net connections per square kilometer varies enormously as between different geographical locations, and access to these technologies still depends very much on where you are located, in both geographical and social space. The distribution of these new technologies frequently mirrors established structures of power, and flows of internet traffic tend to follow the routes laid down by previous forms of communication. Further, as Zook (2005) demonstrates, the economy of the information age is actually rooted in very particular places. Despite the internet's ability to transcend space, the great majority of the world's dot.com companies are clustered in particular parts of a small number of urban conglomerations.

Rather than imagining that we stand on the cusp of an era in which the virtual geography of cyberspace will somehow entirely 'replace' the physical geography of the world, we would perhaps do better to accept that the virtual is now increasingly becoming a banal overlay to the world of the actual. Moreover, I would suggest that speaking of 
'cyberspace' in general may be less useful than recognising that cyberspaces are not only various themselves, but are best characterised by reference to the particular ways in which the virtual and the actual are mixed together in different locations, according to localised cultural rules and priorities.

The same issues arise in relation to the significance of what has recently been described as the analytic shift from stasis to mobility within the social sciences. While sympathetic to the contribution of the 'new mobilities' paradigm developed, in the UK, by Urry et al. (2008), I also take note of Adey's (2006) useful caution that 'If mobility is everything then it is nothing' - which clearly implies the need for a carefully differentiated analyses of access to mobility for people in varying social and geographical locations. Thus, in the context of claims that 'we' live in a culture of speed, we evidently need to also consider the opposite issue - the question of waiting - which is, of course, the fate of the poor, or indeed of all of those who lack the qualifications (financial or otherwise) which give access to the relevant 'fast-track' or priority lane. If, for the middle classes of San Paulo, their 'mobility needs' are increasingly met by helicopters which fly to and from the pads on the rooftops of their apartment buildings, their maids must often travel 4-5 $\mathrm{h}$ each way, by bus, to and from the outlying favelas in which they live. In a similar spirit, Sekula (1995) notes that it may take up to a year for illegal migrants to get from China to Canada by ship, as they must spend days waiting, at various strategic points on their journey, in order to evade customs and border controls. It is these issues to which Massey $(1994,2005)$ points when she insists that we attend to what she calls the powergeometry of contemporary mobilities.

\section{Anthropological and comparative perspectives}

Let me turn now to the question of Euro-centrism in our field. Interpretive paradigms derived from the West have often been imported wholesale and applied elsewhere without being appropriately tailored to the local situation. Moreover, most Western media theory is both self-absorbed and parochial, with the result that universalistic theories about the media are advanced on the basis of evidence derived usually from the same few Euro-American settings. Thus our (supposedly universal) models of the world's media are in fact 'unduly influenced by the experience of a few, untypical 
countries'. Indeed, it is clearly absurd to 'universalise' the particular experience of places such as the USA and Britain, as if these affluent, stable democracies, with their Protestant histories and imperial entanglements, could possibly be seen as representative of the world at large (Curran and Park 2000).

The anthropologist Brian Larkin's starting point (Larkin, 2008) is to ask what media theory would look like, if it began from how the media actually work in a place like the contemporary Nigerian City of Kano, rather than in Europe or the United States? His concern is to examine 'where the insights of [Western] media theory have force' and where their analytical assumptions turn out to be socially or culturally specific, rather than based on any 'essential properties' of the technologies of which they claim to speak.

Larkin uses the Nigerian experience to defamiliarise our presumptions and thus reveal the particularity of 'what goes without saying' in the West. By highlighting processes which are played down in analyses that assume the universal normality of what are, in fact, the specific socio-political configurations of the West, he explicates how these differential conditions might challenge many of our taken-for-granted assumptions.

His fundamental point is well-made in a simple example, where he explicates the quite different significance of an electrical blackout in New York and Kano. In the former, it is experienced as a terrifying disaster - in the latter, as a routine/ momentary annoyance, before people switch over to their private generator. While western media theory routinely assumes the universal availability of well-functioning technological infrastructures, the people of the 'megaslums' of the world live in thoroughly 'privatised' worlds of everyday technological improvisation, where 'making do'/survival strategies, based around fragile and flexible local networks, are always necessary, given the unreliability of all structural forms of provision.

To argue all this is simply to recognise that, empirically speaking, the assumed 'truths' of media studies only pertain to media operating within very particular types of sociocultural, legal and economic frameworks. Thus, to conclude by return- ing to the issue of 'contextualism', before confronting the question of contemporary changes, 
technological or otherwise, we must be sensitive to the very many ways in which contexts produce 'media cultures' in the first place.

Thus, in relation to the dynamics of the global variations within what has been called the 'post-broadcast' era, Turner and Tay (2009) note how easy it is to get carried away by the overwhelming trends in Western media markets, the similarity of which has perhaps encouraged Western scholars to underestimate the contingency of the relations between television, nation and culture to which they are accustomed. Thus, they argue for the need to re-contextualise the 'default-settings' of Anglo-American Television studies - and to shift its focus, so as to better recognise the extent to which local, national and regional histories still determine the contemporary development of global television. This also involves recognising the variety of platforms, formats and distinctive cultural forms currently in play in different geo-linguistic markets. Above all, we must recognise that not all of them are developing in the same direction - let alone, at the same rates - as are the Western media on which most of our theoretical models are based, and to this extent, we should resist any siren calls to extrapolate improperly 'unversalised' perspectives from the development of the contemporary Western media.

Note: This article draws on material which is also discussed, in a different theoretical context, in my 'Television, Technology and Culture' in The Communication Review 2012, Vol 15, 79-105.

\section{References}

Adey, P., 2006. 'If Mobility is Everything, Then it is Nothing' in Mobilities, vol. I. I. pp. 7594.

Bausinger, H., 1990. Folk Culture in a World of Technology Bloomington. Indiana University Press.

Braudel, F., 1984. The Perspective of the World (Civilization and Capitalism, vol. III). Harper and Row, New York.

Bryce, J., 1987. 'Family Time and Television Use: A Contextualist Approach'. In: Lindlof, T. (Ed.), Natural Audiences. Ablex, Norwood, NJ. 
Buerk, R., 2006. Breaking Ships. Chamberlain Bros Publishing, New York.

Curran, J., Park, M.J., (Eds.), 2000. De-Westernising Media Studies, Routledge, London.

Edgerton, D., 2006. The Shock of the Old. Profile Books, London.

du Gay, P., Hall, S., Janes, L., Mackay, H., 1996. Doing Cultural Studies: The Story of the Sony Walkman. Open University Press, Milton Keynes.

Larkin, B., 2008. Signal and Noise Durham. Duke University Press, NC.

Latour, B., 1993. We Have Never Been Modern. Harvester Wheatsheaf, Hemel Hempstead.

Massey, D., 1994. Space, Place and Gender. Polity Press, Cambridge.

Massey, D., 2005. For Space. Sage, London.

Miller, D., Slater, D., 2000. The Internet: An Ethnographic Approach. Berg Publishing, London.

Morley, D., 20I I. 'Communications and Transport: The Mobility of Information, People and Commodities' Media, Culture and Society, vol. 33.5. pp. 743-759.

Sekula, A., 1995. Fish Story Rotterdam: Richter Verlag, Witte de With Centre for Contemporary Art.

Spigel, L., 2004. Introduction. In: Spigel, L., Olsson, J. (Eds.), Television after TV Raleigh.

Duke University Press, Durham, NC.

Turner, G., Tay, J., 2009. Television Studies after TV. Routledge, London.

Urry, J., 2008. Mobilities. Polity Press, Cambridge.

Wark, M., 1994. Virtual Geography. Indiana University Press, Bloomington.

Williams, R., 1965. The Long Revolution. Pelican Books, Harmondsworth.

Zook, M., 2005. The Geography of the Internet Industry. Blackwell, Oxford. 
This article was published in Telematics and Informatics, 30 (20I3) pP 6I-65 